\title{
Certain Investigation on the Development and Recent Trends in Brain Computer Interface- A Review
}

\author{
Saranya K ${ }^{1}$, Dr.M.Paulraj ${ }^{2}$,S.J Savitha ${ }^{3}$ \\ ${ }^{1}$ Assistant Professor, Department of CSE, Sri Ramakrishna Institute of Technology, Coimbatore, India. \\ ${ }^{2}$ Professor, Department of CSE, Sri Ramakrishna Institute of Technology, Coimbatore, India \\ ${ }^{3}$ Assistant Professor, Department of CSE, Sri Ramakrishna Institute of Technology, Coimbatore, India
}

\begin{abstract}
Brain computer interface (BCI) is a system that provides a communication link between the user and their external activities without the help of their peripheral muscles and nerves. This system's efficiency purely depends on the two controllers, who send their commands via EEG and the BCI, which converts the commands into the desired action. This research area is gaining massive attention in recent years by researchers due to its extravagant outputs for physically disabled people. Here this BCI system collects the brain signals or activity from the human brain using various signal collection methodologies and converts those raw signals into meaningful commands that control the external device without their physical help. This ultimate transformation is achieved by multiple transformation techniques through various phases. This paper aims to review the evolution of the $\mathrm{BCI}$; the general framework from which the $\mathrm{BCI}$ is developed, the latest translational algorithms, feature selection strategies, artefact removal methods, and finally the paper is concluded by suggesting the readers the area of exploration in efficient BCI development.
\end{abstract}

Keywords: BCI, EEG, Translational algorithms, Classification techniques

\section{Introduction:}

Communication is the bridge that helps people to share their thoughts and knowledge with other people. Ordinary people communicate their ideas through speech while physically challenged people express their thoughts and feelings using hand gestures. If those people have severe motor disabilities, they need some assistance or help to deliver their thoughts via some medium. BCI is such a system that helps physically disabled people control external devices without their physical body[1,2,3].

BCI collects the brain signal from the human brain using devices like EEG, fMRI, MRI, MEG etc, [4] processes the signals using various techniques and produces control signals to activate external devices or communicate with the external world. EEG machine is the most popular device used by the researchers for their research since the results obtained via this medium have high resolution than others. This method is cost-effective and easy to utilization compared with other devices used to record brain activity.

EEG machine is the device used to record and monitor the various electrical activities in the brain. Such brain signals recordings are useful for diagnosing various brain-related conditions such as Epileptic Seizer, brain death, coma, sleep disorder, encephalopathy, etc. in the medical field. This

Vol. 4 (6), December 2020, www.ijirase.com machine can be used in two different ways one is the invasive method and the other one is non-invasive method $[5,6]$. The former needs technical expertise to work on since the electrodes are to be placed deep inside the skull and expensive. The researchers widely use the latter one since it is easy to work with. In this method, the electrodes are placed on the desired positions on the scalp and the signals are acquired[7,8].

In order to create a Robust BCI system, the transformation of the raw signals follows four different phases to deliver proper commands. The first phase is the signal acquisition, where the brain signals are captured from various devices such as EEG, MRI, MEGetc $[9,10]$. The second phase is the pre-processing, where unwanted noises such as blinking eyes, eye movement, heartbeats, etc have to be removed. The third phase is the most important phase where the noisefree signals are formed into meaningful patterns alias relevant features are extracted depending upon the task that has to be performed by the BCI $[11,12,13]$. This step reduces the dimensionality as well as the computational complexity [14]. The final phase is the classification phase, where the feature signals are separated into classes using powerful algorithms called classifiers to nail the developer's motive.

Due to the vast size of this research area, this paper aims to provide the reader with the evolution of the $\mathrm{BCI}$ with 
respect to usage in recent years and the latest techniques used to model BCI and their advantages and limitations[15].

\section{Pre-processing techniques:}

The EEG signals that are recorded contain unwanted artifacts (eye movement, blinks, movement of muscles etc.,) which deteriorate the main aim of the BCI development process. These contaminated signals largely affect the accuracy of the desired action. Hence, to acquaint the exact brain patterns of individual tasks and eliminate the unwanted noises, a technique is followed called the preprocessing technique. This stage has a tremendous value of pruning out the artifacts leaving back the clean data. The pre-processing step includes three ways, such as avoiding the noises, rejecting the noises, or removal of noises. Some of the common signal enhancement strategies that are used are given in the table below;

\begin{tabular}{|c|c|c|c|c|}
\hline S.NO & TECHNIQUE & CONCEPT & STRENGTH & LIMITATION \\
\hline 1. & $\begin{array}{l}\text { Common } \\
\text { Average } \\
\text { Referencing }\end{array}$ & $\begin{array}{l}\text { It removes the noise by } \\
\text { eliminating the different activity } \\
\text { leaving back the idle activity of } \\
\text { each and every position of the } \\
\text { electrode [16]. }\end{array}$ & $\begin{array}{l}\text { Improved Signal to noise ratio } \\
\text { (SNR). Gives good result for } \\
\text { motor imagery tasks. }\end{array}$ & $\begin{array}{l}\text { Incomplete head } \\
\text { coverage[17,18]. }\end{array}$ \\
\hline 2. & $\begin{array}{l}\text { Adaptive } \\
\text { filtering }\end{array}$ & $\begin{array}{l}\text { It tries to model the relationship } \\
\text { between different signals } \\
\text { iteratively. }\end{array}$ & $\begin{array}{l}\text { Works well for signals and } \\
\text { interferences with overlapping } \\
\text { spectra [17]. }\end{array}$ & $\begin{array}{l}\text { Need of reference } \\
\text { signal. }\end{array}$ \\
\hline 3. & $\begin{array}{l}\text { Surface } \\
\text { laplacian }\end{array}$ & $\begin{array}{l}\text { It is an effective spatial filter } \\
\text { used to improve SNR. It } \\
\text { estimates the density entering } \\
\text { and exiting the skull[19]. }\end{array}$ & $\begin{array}{l}\text { Robust against the artifacts } \\
\text { emerging outside the covered } \\
\text { regions and solves the } \\
\text { electrode } \\
\text { problem[20]. }\end{array}$ & $\begin{array}{l}\text { Sensitive to artifacts } \\
\text { and spline pattern } \\
{[21] \text {. }}\end{array}$ \\
\hline 4. & $\begin{array}{l}\text { Common } \\
\text { spatial } \\
\text { patterns(CSP) }\end{array}$ & $\begin{array}{l}\text { CSP transforms the EEG signal } \\
\text { into variance matrix that } \\
\text { discriminates between various } \\
\text { classes [20]. It is highly } \\
\text { sensitive to electrode position. It } \\
\text { uses spatial filtering for pattern } \\
\text { recognition [22]. }\end{array}$ & $\begin{array}{l}\text { Does not need any pre } \\
\text { selection or knowledge of } \\
\text { bands [20]. }\end{array}$ & $\begin{array}{l}\text { Sensitive to } \\
\text { electrode position. }\end{array}$ \\
\hline 5. & $\begin{array}{l}\text { Independent } \\
\text { component } \\
\text { analysis (ICA) }\end{array}$ & $\begin{array}{l}\text { It separates the noises from } \\
\text { EEG signal into independent } \\
\text { components based on the } \\
\text { characteristics of data without } \\
\text { depending on electrode } \\
\text { positions [17]. }\end{array}$ & $\begin{array}{l}\text { Computationally efficient for } \\
\text { huge amount of data [23]. }\end{array}$ & $\begin{array}{lr}\text { Need } & \text { more } \\
\text { computation } & \text { for } \\
\text { decomposition. } & \end{array}$ \\
\hline 6. & $\begin{array}{l}\text { Principal } \\
\text { component } \\
\text { analysis. }\end{array}$ & $\begin{array}{l}\text { It transforms the set of } \\
\text { correlated vectors into linearly } \\
\text { uncorrelated vectors which is } \\
\text { known as "principal } \\
\text { components" }[22,24]\end{array}$ & $\begin{array}{l}\text { Helps in reduction of feature } \\
\text { dimension. }\end{array}$ & $\begin{array}{l}\text { Not as good as ICA } \\
{[20] \text {. }}\end{array}$ \\
\hline
\end{tabular}




\section{Feature Selection techniques:}

High dimensionality is a curse for classifying the data in various fields. Reduction of dimensionality can be done in two ways, namely feature selection and feature extraction techniques depending upon the various aspects of the dataset and prediction that has to be made. Feature selection relies more on the feature engineering process rather than the analysis part, here a subset of best input features are selected without affecting other features. Feature extraction transforms the original feature set and gives a composite feature set. Selecting the features without losing the information depends on the robustness of various algorithms used to discriminate classes.

Initially, the original input variables are used to generate the subset features by removing irrelevant and redundant data without losing any information and fed into the learning machine. The performance of the selected features is evaluated. If the performance is improved, the final subset of features is generated else, the process starts from the subset selection phase. The final best subset will be validated using different tests.

Basically, the feature selection techniques are categorized into three types namely filter, wrapper and embedded method [25]. The filter method selects the subset of features based on their intrinsic characteristics of data independent of the mining algorithm; it is good for the computation of high dimensional data[26]. The wrapper method requires predetermined data to produce a better subset of features. The embedded method utilizes the filter and the wrapper method to produce best results [26]. The characteristics of the feature selection are shown in fig 2.

An outline of basic feature selection algorithms is given in the paper[3] by Ladla et al.Based on the characteristics of the feature selection method such as search organisation, feature generation and evaluation measure, nine feature selection methods are compared and contrasted in the paper [28] and shown in the table below;

\begin{tabular}{|c|c|c|c|c|}
\hline ALGORITHM & $\begin{array}{l}\text { SEARCH } \\
\text { ORGANISATION }\end{array}$ & $\begin{array}{l}\text { FEATURE } \\
\text { GENERATION }\end{array}$ & $\begin{array}{l}\text { EVALUATION } \\
\text { MEASURE }\end{array}$ & CONCEPT \\
\hline $\begin{array}{l}\text { Correlation } \\
\text { coefficient }\end{array}$ & Sequential & Forward selection & Divergence & $\begin{array}{l}\text { Evaluates how well an } \\
\text { induvidual } \\
\text { contributes to the seperation } \\
\text { of class[33]. }\end{array}$ \\
\hline $\begin{array}{l}\text { Between } \\
\text { Within(BW)-ratio }\end{array}$ & Sequential & - & Divergence & $\begin{array}{l}\text { It finds the ratio of between } \\
\text { group and within group and } \\
\text { selects the feature with high } \\
\text { BW ratio. It is useful for } \\
\text { selecting group of feature } \\
\text { from feature space [29]. }\end{array}$ \\
\hline $\begin{array}{l}\text { Prediction Analysis } \\
\text { of } \\
\text { Microarray(PAM) }\end{array}$ & Sequential & Weighted & Distance & $\begin{array}{l}\text { It does class prediction } \\
\text { using gene expression. It } \\
\text { selects the best gene subset } \\
\text { by using shrunken centroid } \\
{[30] \text {. }}\end{array}$ \\
\hline $\begin{array}{l}\text { Minimal } \\
\text { Redundancy } \\
\text { maximum Array } \\
(\mathrm{mRmR})\end{array}$ & Random & Forward selection & $\begin{array}{l}\text { Mutual } \\
\text { information }\end{array}$ & $\begin{array}{l}\text { It finds the mutual } \\
\text { dependency between two } \\
\text { variables. It minimizes the } \\
\text { redundancy [33]. }\end{array}$ \\
\hline I-RELIEF & Random & Weighted & Distance & $\begin{array}{l}\text { It finds the relevance of } \\
\text { features in the neighborhood } \\
\text { around the target[33]. }\end{array}$ \\
\hline $\begin{array}{l}\text { Conditional Mutual } \\
\text { Information }\end{array}$ & Sequential & Forward selection & $\begin{array}{l}\text { Conditional } \\
\text { mutual }\end{array}$ & $\begin{array}{l}\text { It finds the feature that has } \\
\text { maximum relevance to thye }\end{array}$ \\
\hline
\end{tabular}

Vol. 4 (6), December 2020, www.ijirase.com 


\begin{tabular}{|l|l|l|l|l|}
\hline $\begin{array}{l}\text { Maximization(CMI } \\
\text { M) }\end{array}$ & Sequential & $\begin{array}{l}\text { Backward } \\
\text { elimination }\end{array}$ & Consistency & $\begin{array}{l}\text { larget class using } \\
\text { conditional mutual } \\
\text { information [33] }\end{array}$ \\
\hline Interact & $\begin{array}{l}\text { It finds the interaction } \\
\text { among theatures by } \\
\text { backward elimination } \\
\text { measuring the consistency }\end{array}$ \\
\hline Genetic Algorithm & Random & Weighted & Consistency & $\begin{array}{l}\text { It uses natural biological } \\
\text { process and randomized } \\
\text { search for finding the } \\
\text { feature subset which is } \\
\text { represented in strings[30] }\end{array}$ \\
\hline $\begin{array}{l}\text { SVM Recursive } \\
\text { Feature } \\
\text { Elimination(SVM- } \\
\text { REF) }\end{array}$ & Sequential & $\begin{array}{l}\text { Backward } \\
\text { elimination/weigh } \\
\text { ted }\end{array}$ & information & $\begin{array}{l}\text { It finds the features which } \\
\text { leads to the largest margin } \\
\text { of class seperation and does } \\
\text { ranking[31] }\end{array}$ \\
\hline
\end{tabular}

\section{Classification techniques:}

After selecting the relevant features, the subset is given as an input to various classifiers to do the classification process. The famous classifiers used in the BCI development are Linear classifiers, Neural Networks, Non linear Baysien classifier, Nearest neighbour classifier, and Hybrid classifiers.

Linear Classifiers: These are the popular classifiers that are used in the BCI development process. Here the linear functions are used to distinguish the feature sets to various classes. Two main algorithms used in this category are;

Linear Discriminant Analysis (LDA) : It mainly uses hyperplanes to separate the features between different classes this technique has less computational requirement and produce good result with ease of use, so it is widely used in BCI systems such as motor imagery based BCI,P300 $\mathrm{BCI}$, asynchronous BCI's [ 34,35,36,37]. The main drawback is that it may produce poor results for nonlinear EEG data.

Support Vector Machine(SVM): it also uses the hyperplanes to separate data but the margins are maximized here rather than LDA, which causes more generalization. It is mostly applied to synchronous BCI problems and has produced good results $[36,38,39]$. The main advantage of SVM is that it has good generalization properties and it reduces the curse of dimensionality.
Neural networks(NN):It produces nonlinear decision boundaries using several artificial neurons[40]. The most widely used NN is Multilayer Perceptron.

Multilayer Perception (MP): it generally has one input layer, one or more hidden layers, and one output layer. The neurons are connected in a pipelined manner, such as the input neuron is connected with the output of the previous neuron. The neuron of the output layer classifies the input feature. NN has been widely used in solving many of the BCI problems such as synchronous, asynchronous, binary and multiclass BCI. Without a hidden layer, MP is called as a perceptron and it produces results equal to LDA. One of the important $\mathrm{NN}$ architectures is Gaussian Classifier [41,42], which has been created explicitly for BCI.

Non- Linear Bayesian Classifiers: These classifiers are used to produce non linear decision boundaries and efficient removal of uncertain samples. This has not been widely used nowadays in BCI development because it is not as fast as other techniques. The major two types of Bayesian classifiers are Bayes quadratic and Hidden Markov model(HMM).

Bayes quadratic: It assigns the feature vector with the highest probability to the class it belongs to[43,44]. The probability is calculated using the MAP (Maximum A Posteriori) rule [49]. Even though this classifier is not widely used it the BCI development process, it has shown good success rates when classifying motor imagery[45,46] and mental tasks $[47,48]$. 
Hidden Markov Model (HMM): HMM is one of the most popular dynamic classifiers that classify time series data [50]. It uses a probabilistic approach for classifying the feature vectors; In BCI this approach is called Gaussian Mixture Models(GMM) [52]. Another type of HMM is Input output HMM or IOHMM these type of HMM can discriminate several classes rather than that of the HMM [51].

Nearest Neighbour Classifiers: These are relatively simple classifiers by simply assigning the feature vectors to the class which are present as their nearest neighbours. This assigning operation is generally done by calculating the distance between the feature vectors. The nearest neighbour can either be a feature vector from the training set (kNN) or from a class model (Mahalanobis distance).

K Nearest Neighbour: By using the distance metric [38] the nearest neighbours of the feature vector within the training set are calculated and assigned to the relevant class. It produces nonlinear decision boundaries with high value of " $\mathrm{k}$ " and a sufficient amount of training samples. The main limitation here is that the classifier is very sensitive and has a dimensionality curse [53]. Mahalanobis distance: It assumes a Gaussian distribution for each model of the class and assigns the feature vectors to each model of the class depending upon their nearest distance measure. It acts as a robust classifier for multiclass and asynchronous BCI's [54].
Hybrid classifiers: These are the recent trends in BCI development process since different classifiers' aggregation provides robust results. The combining strategy is followed because it reduces the variance as well as classification errors. The techniques used in combining different classifiers are as follows;

Boosting: It is a multilayered approach of several classifiers, each classifier focuses on the previous classifier's weakness [55]; hence it builds a powerful classifier. The limitation here is it could lead to mislabels [56]. This method has been tested with MLP and OLP [57,58].

Voting: Here, several classifiers are used to assign the feature vectors to a particular class finally, the majority will win the race [56]. This method has been widely used in BCI research due to its simplicity and efficiency.

Stacking: In this approach, the feature vector is initially given to one classifier, which is called as the level-0 classifier. The output of this is given to the next classifier called level 1 classifier or the meta classifier and this classifier gives the final decision [59]. Mostly HMM is used as a level 0 classifier ans SVM is used as a Meta classifier [60].

\section{Recent Trends in BCI development:}

Some of the recent researches that are carried out in BCI are as follows:

\begin{tabular}{|l|l|l|l|l|l|}
\hline S.no & Paper name\& Author & $\begin{array}{l}\text { Journal } \\
\text { \& year }\end{array}$ & $\begin{array}{l}\text { Feature } \\
\text { extraction/selection } \\
\text { technique }\end{array}$ & $\begin{array}{l}\text { Classification } \\
\text { technique }\end{array}$ & Application \\
\hline 1 & $\begin{array}{l}\text { EEG based Strategies to } \\
\text { Detect Motor imagery for } \\
\text { Control and Rehabilitation }\end{array}$ & $\begin{array}{l}\text { IEEE } \\
2017\end{array}$ & $\begin{array}{l}\text { Filter Bank Common } \\
\text { Spatial Pattern } \\
\text { (FBCSP) algorithm / } \\
\text { Mutual information }\end{array}$ & Adaptive & $\begin{array}{l}\text { Motor imagery for } \\
\text { Control and }\end{array}$ \\
\hline 2 & $\begin{array}{l}\text { TimbreClassificationMeth } \\
\text { od Based On The Common } \\
\text { Spatial PatternFilter }\end{array}$ & $\begin{array}{l}\text { IEEE } \\
\text { Ratitation }\end{array}$ & $\begin{array}{l}\text { Common Spatial } \\
\text { Pattern (CSP) }\end{array}$ & Covariance matrix & Timbre \\
\hline 3 & $\begin{array}{l}\text { Classification } \\
\text { OfComputed Tomography } \\
\text { Scanner Manufacturer } \\
\text { Using Support Vector } \\
\text { Machine }\end{array}$ & $\begin{array}{l}\text { IEEE } \\
\text { Classification }\end{array}$ & Density distribution & $\begin{array}{l}\text { Support Vector } \\
\text { Machine(SVM) }\end{array}$ & $\begin{array}{l}\text { Quantitative CT } \\
\text { analysis }\end{array}$ \\
\hline
\end{tabular}




\begin{tabular}{|c|c|c|c|c|c|}
\hline 4 & $\begin{array}{l}\text { Design and Evaluation of a } \\
\text { P300-ERP based BCI } \\
\text { System for Real-Time } \\
\text { Control of a Mobile Robot }\end{array}$ & $\begin{array}{l}\text { IEEE } \\
2017\end{array}$ & ERP Spectrally Filter. & $\begin{array}{l}\text { Regularized } \\
\text { logistic regression }\end{array}$ & $\begin{array}{l}\text { To control a mobile } \\
\text { robot } \\
\text { Platform into four } \\
\text { directions (left, } \\
\text { right, front, back). }\end{array}$ \\
\hline 5 & $\begin{array}{l}\text { An Online Self-paced } \\
\text { Brain-Computer Interface } \\
\text { Onset Detection Based On } \\
\text { Sound-production Imagery } \\
\text { Applied To Real-life } \\
\text { Scenarios. }\end{array}$ & $\begin{array}{l}\text { IEEE } \\
2017\end{array}$ & $\begin{array}{l}\text { Autoregressive } \\
\text { Coefficients, Band } \\
\text { Power, Common } \\
\text { Spatial Patterns And } \\
\text { Discrete } \\
\text { Wavelet Transform }\end{array}$ & $\begin{array}{l}\text { Linear } \\
\text { Discriminant } \\
\text { Analysis (LDA) }\end{array}$ & $\begin{array}{l}\text { Onset Detection } \\
\text { Based On Sound- } \\
\text { production } \\
\text { Imagery }\end{array}$ \\
\hline 6. & $\begin{array}{l}\text { Conceptual Analysis of } \\
\text { Epilepsy Classification } \\
\text { Using Probabilistic } \\
\text { Mixture Models }\end{array}$ & $\begin{array}{l}\text { IEEE } \\
2017\end{array}$ & $\begin{array}{l}\text { Power Spectral } \\
\text { Density (PSD) }\end{array}$ & $\begin{array}{l}\text { Gaussian Mixture } \\
\text { Model } \\
(\mathrm{GMM})\end{array}$ & $\begin{array}{l}\text { The detection of the } \\
\text { abnormal EEG } \\
\text { segments which } \\
\text { relates to } \\
\text { The activities of the } \\
\text { seizure. }\end{array}$ \\
\hline 7. & $\begin{array}{l}\text { Classification } \\
\text { Of Midazolam-Induced } \\
\text { Sedation Depth Based On } \\
\text { Spatial And Spectral } \\
\text { Analysis }\end{array}$ & $\begin{array}{l}\text { IEEE } \\
2017\end{array}$ & $\begin{array}{l}\text { GFS [Using } \\
\text { Coefficients Of } \\
\text { Multidimensional } \\
\text { Channels } \\
\text { InInterestFrequency } \\
\text { Range] }\end{array}$ & $\begin{array}{l}\text { Linear } \\
\text { Discriminant } \\
\text { Analysis } \\
\text { (LDA) }\end{array}$ & $\begin{array}{l}\text { Classification } \\
\text { Between The } \\
\text { WakefulnessAnd } \\
\text { Unconsciousness } \\
\text { Under Midazolam- } \\
\text { induced Patient- } \\
\text { controlled Sedation } \\
\text { (PCS) }\end{array}$ \\
\hline 8 & $\begin{array}{l}\text { Identification of Attention } \\
\text { State for } \\
\text { using In-Ear-Selection } \\
\text { Recording }\end{array}$ & $\begin{array}{l}\text { IEEE } \\
2017\end{array}$ & Fisher ratio & $\begin{array}{l}\text { Support Vector } \\
\text { Machine(SVM) }\end{array}$ & $\begin{array}{l}\text { the attention state } \\
\text { recorded from in- } \\
\text { ear EEG was } \\
\text { discriminated from } \\
\text { the resting state to } \\
\text { use simple } \\
\text { application of one- } \\
\text { button menu } \\
\text { selection }\end{array}$ \\
\hline
\end{tabular}




\begin{tabular}{|c|c|c|c|c|c|}
\hline 9 & 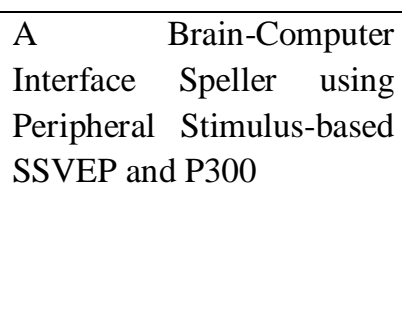 & $\begin{array}{l}\text { IEEE } \\
2017\end{array}$ & $\begin{array}{l}\text { Canonical Correlation } \\
\text { Analysis (CCA) }\end{array}$ & $\begin{array}{l}\text { Linear } \\
\text { Discriminant } \\
\text { Analysis (LDA) }\end{array}$ & $\begin{array}{l}\text { A novel hybrid } \\
\text { speller that is } \\
\text { SSVEP feedback } \\
\text { with peripheral- } \\
\text { vision stimulus to } \\
\text { the conventional } \\
\text { P300 paradigm. }\end{array}$ \\
\hline 10 & $\begin{array}{l}\text { Riemannian } \text { Geometry } \\
\text { Applied to Detection of } \\
\text { Respiratory States from } \\
\text { EEG Signals: the Basis for } \\
\text { a Brain-Ventilator } \\
\text { Interface }\end{array}$ & $\begin{array}{l}\text { IEEE } \\
2016\end{array}$ & $\begin{array}{l}\text { Covariance } \\
\text { matrices }(\mathrm{CM})\end{array}$ & $\begin{array}{l}\text { k- means } \\
\text { clustering }\end{array}$ & $\begin{array}{l}\text { Detects patient- } \\
\text { ventilator } \\
\text { disharmony when } \\
\text { verbal } \\
\text { communication is } \\
\text { difficult. }\end{array}$ \\
\hline
\end{tabular}

\section{Conclusion:}

This paper has reviewed the history of BCI development, various data acquisition methodologies with their strengths and weaknesses, pre-processing techniques with their advantages and limitations; feature selection techniques with their evaluation measure; classification techniques and the recent research in BCI development. This review depicts only the most popular or generalized techniques and methods used in the BCI development process. There are a lot more in-depth to explore in this field as it develops rapidly and introduces new ideas to all the issues related to human-machine interaction. In order to develop and launch a successful BCI in society, the system needs to be fast enough and produce accurate results. These two criteria can be achieved only if we have interdisciplinary research among the researchers. The readers are suggested to focus on these criteria to develop a robust BCI by analyzing society's desires and needs.

\section{REFERENCES:}

1.Saeid, S., \& Jonathon, C. (2007). EEG signal processing.WileyInterscience.

2.Vrushali R ."survey on brain computer interaction" in IJAREEIE, vol 2,issue 4,april 2013

3.http://www.brainvision.co.uk/blog/2014/04/the-brief-history-ofbrain-computer-interfaces

4. He B, Gao S, Yuan H, Wolpaw JR. Brain-computer interfaces.Neural Engineering.Springer; 2013.

5. Hochberg LR, Serruya MD, Friehs GM, Mukand JA, Saleh M, Caplan AH, Branner A, Chen D, Penn RD, Donoghue JP. Neuronal ensemble control of prosthetic devices by a human with tetraplegia. Nature 2006;442(7099):164-71.

6. John, "Where Do The Electrodes Go?" [Online]. Available: http: //www.diytdcs.com/tag/1020-positioning/

7. Wolpaw, J. R., \& M. Hallett, L. H. P. I. I. D. L. S. a. J. M. M. (2004). Chapter 64 Brain-computer interfaces (BCIs) for Vol. 4 (6), December 2020, www.ijirase.com communication and control: a mini-review. In Supplements to Clinical Neurophysiology (Vol. Volume 57, pp. 607-613): Elsevier.

8. White, C. T., Kataoka, R. W., \& Martin, J. I. (1977). Colour evoked potentials: development of a methodology for the analysis of the processes involved in colour vision. Visual Evoked Potentials in Man, New Developments, Clarendon Press, Oxford, 250 \pm 272 .

9. Palaniappan, R. (2005, 16-19 March 2005). Brain Computer Interface Design Using Band Powers Extracted During Mental Tasks. Paper presented at the 2nd International IEEE EMBS Conference on Neural Engineering,321-324.

10. Manolas, M. G., Stamoulos, T. D., \&Anninos, P. A. (1999). Differences in human visual evoked potentials during the perception of colour as revealed by a bootstrap method to compare cortical activity.A prospective study. Neuroscience Letters, 270(1), 21-24.

11. Lalor, E. C., Kelly, S. P., Finucane, C., Burke, R., Smith, R., Reilly, R. B., et al. (2005). Steady-state VEP-based braincomputer interface control in an immersive 3D gaming environment. Eurasip Journal on Applied Signal Processing, 2005(19), 3156-3164.

12. Wolpaw, J. R., Birbaumer, N., Heetderks, W. J., McFarland, D. J., Peckham, P. H., Schalk, G., et al. (2000). Brain-computer interface technology: a review of the first international meeting. IEEE Transactions on Rehabilitation Engineering, 8(2), 164-173.

13. Rader, B., Rasler, F., Hennighausen, E., \&Naker, F. (1996). Event-related potentials during auditory and somatosensory discrimination in sighted and blind human subjects. Cognitive Brain Research, 4(2), 77-93.

14. Birbaumer, N. (1997). Slow cortical potentials: their origin, meaning, and clinical use. Brain and Behavior Past, Present, and Future, 25-39.

15. E. Donchin, "The mental prosthesis: assessing the speed of a P300-based brain-computer interface," . . . , IEEE Transactions on, vol. 8, no. 2, pp. 174-179, 2000.

16. X. Yu, P. Chum, and K.-B.Sim, "Analysis the effect of PCA forfeature reduction in non-stationary EEG based motor imagery of BCIsystem," Optik - International Journal for Light and Electron Optics, vol. 125, pp. 1498-1502, 2// 2014

17. M. R. Lakshmi, D. T. V. Prasad, and D. V. C. Prakash, "Survey onEEG Signal Processing Methods," International 
Journal of AdvancedResearch in Computer Science and Software Engineering, vol. 4, pp.84-91, 2014.

18. Mohammed J. Alhaddad, "Common Average Reference ( CAR )Improves P300 Speller," International Journal of Engineering andTechnology, vol. 2, pp. 451-489, 2012.

19. Mohammed J. Alhaddad, "Common Average Reference ( CAR )Improves P300 Speller," International Journal of Engineering andTechnology, vol. 2, pp. 451-489, 2012.

20.AbhijeetMallick et al.," A Review on Signal Pre-processing Techniques in Brain Computer Interface", International Journal of Computing and Technology( IJCAT), Volume 2 ,issue 4, April 2015.

21. MohdZaizullyas et al.," A Survey of Analysis and Classification of EEGSignals for Brain-Computer Interfaces", 2015 2nd International Conference on Biomedical Engineering (ICoBE), 30-31 March 2015, Penang.

22. Fabien Lotte and Cuntai Guan, Regularizing CommonSpatial Patterns to Improve BCI Designs: UnifiedTheory and New Algorithms, IEEE Trans. OnBiomedical Engg., Vol. 58, No. 2, 2011.

23. G. Korats, S. Le Cam, R. Ranta, and M. Hamid, "Applying ICA inEEG: Choice of the Window Length and of the DecorrelationMethod," in Biomedical Engineering Systems and Technologies. vol.357, J. Gabriel, J. Schier, S. Van Huffel, E. Conchon, C. Correia, A.Fred, et al., Eds., ed: Springer Berlin Heidelberg, 2013, pp. 269-286.

24. A Garcés Correa, E Laciar, M E Valentinuzzi, H DPatiño, Artifact removal from EEG signals usingadaptive filters in cascade, 16th ArgentineBioengineering Cong. and the 5th Conf. of ClinicalEngg., IOP Publishing J. of Physics: Conf. Series 90(2007)

25. Lei Yu, Huan Liu, "Feature Selection for High-Dimensional Data: A Fast Correlation-Based Filter Solution”, Department of ComputerScience \& Engineering, Arizone State University, Tempe, AZ 85287-5406, USA, 2003.

26. K. Sutha et al "A Review of Feature Selection Algorithms for Data Mining Techniques" International Journal on Computer Science and Engineering (IJCSE) ISSN : 09753397 Vol. 7 No.6 Jun 2015.

27. L. Ladla and T. Deepa, "Feature Selection Methods And Algorithms",International Journal on Computer Science and Engineering (IJCSE), vol.3(5), pp. 1787-1797, 2011.

28. C. Yun and J. Yang, "Experimental Comparison of Feature SubsetSelection Methods", In: Seventh IEEE International Conference on DataMining- workshop, pp. 367-372, 2007.

29. Z. Zhao, H. Liu, "Searching for Interacting Features", Proceedings ofInternational Joint Conference on Artificial Intelligence, pp. 1156-1161,2007.

30. R.Tibshirani, T.Hastie, B.Narasimhan and G.Chu, "Diagnosis ofMultiple Cancer Types by Shrunken Centroids of Gene Expression", In;Proceedings of the National Academy of Sciences of the United Statesof America, Vol. 99(10), pp. 6567-6572, 2002.

31.S. Lei, "A Feature Selection Method Based on Information Gain andGenetic Algorithm", In: International Conference on Computer Sciencesand Electronics Engineering, pp. 355-358, 2012.

32. I. Guyon et al, "Gene Selection for Cancer Classification using SupportVector Machines", Machine Learning, Vol. 46(1-3), pp. 389-422, 2002.

33. Samina Khalid et al.," A Survey of Feature Selection and Feature Extraction Techniques in Machine Learning", Science and Information Conference 2014 August 27-29, 2014 | London, UK.
34 G. Pfurtscheller.Eeg event-related desynchronization (erd) and event-related synchronization (ers). 1999.

35 V. Bostanov. Bci competition 2003 data sets ib and iib: feature extraction from event-related brainpotentials with the continuous wavelet transform and the t-value scalogram. IEEE Transactionson Biomedical Engeneering, 51(6):1057\{1061, 2004.

36 D. Garrett, D. A. Peterson, C. W. Anderson, and M. H. Thaut. Comparison of linear, nonlinear, and feature selection methods for eeg signal classi_cation. IEEE Transactions on Neural Systemand Rehabilitation Engineering, 11:141\{144, 2003.

37 R. Scherer, G. R. Muller, C. Neuper, B. Graimann, and G. Pfurtscheller. An asynchronouslycontrolled eeg-based virtual keyboard: Improvement of the spelling rate. IEEE Transactionson Biomedical Engineering, 51(6), 2004.

38. B. Blankertz, G. Curio, and K. R. Muller. Classifying single trial eeg: Towards brain computerinterfacing. Advances in Neural Information Processing Systems (NIPS 01), 14:157\{164, 2002.

39. A. Rakotomamonjy, V. Guigue, G. Mallet, and V. Alvarado.Ensemble of svms for improvingbrain computer interface p300 speller performances.In International Conference on ArtificialNeural Networks, 2005.

40. C. M. Bishop. Neural Networks for Pattern Recognition.Oxford University Press, 1996.

41 J. R. Mill_an, J. Mourio, F. Cincotti, F. Babiloni, M. Varsta, and J. Heikkonen.Local neural classifier for eeg-based recognition of mental tasks.In IEEE-INNS-ENNS International JointConference on Neural Networks, 2000.

42 J. R. Mill_an, F. Renkens, J. Mourino, and W. Gerstner. Noninvasive brain-actuated control of amobile robot by human eeg. IEEE Transactions on Biomedical Engineering, 51(6): $1026\{1033,2004$.

43. R. O. Duda, P. E. Hart, and D. G. Stork.Pattern Recognition, second edition.WILEYINTERSCIENCE,2001.

44. A. Schlogl, F. Lee, H. Bischof, and G. Pfurtscheller. Characterization of four-class motor imageryeeg data for the bci-competition 2005. Journal of Neural Engineering, 2005.

45. S. Lemm, C. Schafer, and G. Curio.Bci competition 2003 \{data set iii: probabilistic modeling ofsensorimotor mu rhythms for classification of imaginary hand movements. IEEE Transactions on Biomedical Engineering, 51(6):1077\{1080, 2004.

46. S. Solhjoo and M. H. Moradi. Mental task recognition: A comparison between some of classificationmethods. In BIOSIGNAL 2004 International EURASIP Conference, 2004.

47.Z. A. Keirn and J. I. Aunon. A new mode of communication between man and his surroundings.IEEE Transactions on Biomedical Engineering, 37(12), 1990.

48.G. A. Barreto, R. A. Frota, and F. N. S. de Medeiros. On the classification of mental tasks:a performance comparison of neural and statistical approaches. In Proceedings of the IEEEWorkshop on Machine Learning for Signal Processing, 2004.

49. K. Fukunaga. Statistical Pattern Recognition, seconde edition. ACADEMIC PRESS, INC, 1990.

50. L. R. Rabiner. A tutorial on hidden markov models and selected applications in speech recognition.In Proceedings of the IEEE, pages $257\{286,1989$.

51. S. Chiappa and S. Bengio. Hmm and iohmm modeling of eeg rhythms for asynchronous bcisystems. In European Symposium on Arti_cial Neural Networks ESANN, 2004.

52. B. Obermeier, C. Guger, C. Neuper, and G. Pfurtscheller Hidden markov models for online classification of single trial eeg. Pattern recognition letters, pages $1299\{1309,2001$. 
53. J. H. K. Friedman. On bias, variance, 0/1-loss, and the curseof-dimensionality.Data Mining andKnowledge Discovery, 1(1), 1997.

54. F. Cincotti, A. Scipione, A. Tiniperi, D. Mattia, M.G. Marciani, J. del R. Mill_an, S. Salinari,L. Bianchi, and F. Babiloni. Comparison of di_erent feature classi_ers for brain computerinterfaces. In Proceedings of the $1^{\text {st }}$ International IEEE EMBS Conference on NeuralEngineering, 2003.

55. R. O. Duda, P. E. Hart, and D. G. Stork.Pattern Recognition, second edition.WILEYINTERSCIENCE,2001.

56. A.K. Jain, R.P.W. Duin, and J. Mao. Statistical pattern recognition : A review. IEEETransactions on Pattern Analysis and Machine Intelligence, 22(1):4\{37, 2000.

57. R. Boostani and M. H. Moradi.A new approach in the bci research based on fractal dimensionas feature and adaboost as classi_er. Journal of Neural Engineering, 1(4):212\{217, 2004.

58. U. Ho_mann, G. Garcia, J.-M. Vesin, K. Diserens, and T. Ebrahimi. A boosting approach to p300detection with application to brain-computer interfaces. In Conference Proceedings of the $2^{\text {nd }}$ International IEEE EMBS Conference on Neural Engineering, 2005.

59 D.H. Wolpert.Stacked generalization.Neural Networks, $5: 241\{259,1992$.

60. H. Lee and S. Choi. Pca+hmm+svm for eeg pattern classification. In Proceedings of the SeventhInternational Symposium on Signal Processing and Its Applications, 2003. 